\title{
Simulation: Early Detection of Brain Vessels Stroke by Applying Electromagnetic Waves Non-Invasively
}

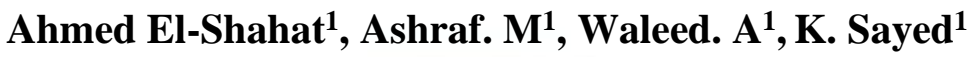 \\ ${ }^{1}$ Electrical Engineering Department, Benha Faculty of Engineering, Benha University, Benha, Egypt.
}

\section{Abstract}

Introduction: Early recognition of stroke with its two types Ischemic and Hemorrhagic, is one of the most crucial research points, commonly used methods are CT- (computerized tomography), and MRI- (Magnetic resonance imaging). These techniques cause a delay in the detection of the condition, which causes permanent disability. The main reason behind the fatal consequences of stroke is the delay of detection. Therefore, this research paper aims to early detection of the type of stroke without delay until the appropriate diagnosis of each type is made, and then the appropriate treatment without delay.

Method: Using a non-invasive and fast technique to determine the stroke type by wave, we simulate and design a vessel containing a liquid as a laminar flow with the same density and velocity of blood, and it was surrounded by a Homogenized multi-turn coil consisting of (n) turns to represent the magnetic field, using specific frequency (HZ) with Electrical field in coil current (A) to see the changing in magnetic flux density (MFD), Depending on the changes in MFD, the flow of blood in laminar flow can be affected by clotting (Ischemic) or Hemorrhagic (cutting) in our vessel designed. We have built three different scenarios to apply the technique which are: First: Normal Scenario (where the blood in vessel has no problem), second: clotting (ischemic, where the vessel blocked in specific three position) and Third: Cutting (Hemorrhagic, where the vessel cut in certain nine positions).

Results: This paper presents-through our own design-the studying of applying the electromagnetic waves on blood inside the vessel to detect the stroke type in our three scenarios (normal, ischemic three positions or hemorrhagic nine positions), Studying the magnetic field and laminar flow. This study covered in three areas. First: coil geometry analysis, Second: stationary, and Third: frequency domain. through the changes in Magnetic Flux Density -MFD- waves. The results were promising and distinct for distinguishing between the three scenarios which are normal, ischemic ( 3 positions) and hemorrhagic ( 9 positions) the results of MFD are: 0.09 to $3.3^{*} 10^{\wedge}-3,0.08$ to $3.15^{*} 10^{\wedge}-4,0.15$ to $6.2^{*} 10^{\wedge}-3$ respectively.

Keywords - Stroke recognition, Brain Stroke, Non-Invasive stroke detection, Stroke simulation, Vessel modeling.

\section{Introduction}

In order to increase the impact of the study, a vital topic was chosen by thinking of a new method that saves the time required to identify the type of stroke [1-3] and provides many patients with the time needed for the treatment process so that complications and permanent disabilities do not occur due to this delay in discovery through the available technologies. Stroke is one of the research areas that need a lot of effort, as it dramatically affects the person who suffers from it. As is well known, stroke occurs when a blood vessel that feeds the brain gets blocked (ischemic stroke) or bursts (hemorrhagic stroke). Then that part of the brain cannot work, nor can the part of the body it controls.

Stroke causes the death of more than six million people annually, while $70 \%$ of those who recover from it live the rest of their lives with permanent disability. The main reason behind the fatal consequences of stroke is the delay of detection.

Predetecting of Stroke type: [Ischemic which is a clot in a vessel in the brain or Hemorrhagic which is caused by bleeding in the brain) using scanning by CT (computerized tomography) [4,5] or MRI (Magnetic resonance imaging) [6-8], These available techniques for stroke detection, despite their vast potentials, and apart from the continuous development, do not help in the early detection of a stroke to reduce death or permanent disability for millions of people. So, it has some delay in detecting the stroke type in many scenarios.

The main goal in this study is to predilect stroke by changing in waves MFD (Magnetic Flux Density), which is the amount of magnetic flux through a unit area taken perpendicular to the direction of magnetic flux, so, Magnetic Flux is the total number of 
magnetic field lines passing through a given area. In the magnetic flux formula $\mu$ is the permeability of the medium (material) where we are measure the fields. We use simulation Multiphysics between our designed geometry as a model to represent the vessel and magnetic fields with laminar flow and frequency to determine fast detection of brain stroke by noninvasive technique [9-13]. This noninvasive technique Does not require physical interference such as CT and MRI as imaging devices available technique, it is provided It requires shining electromagnetic waves at a certain distance from the artery according to the scenarios mentioned later, and then measuring the extent to which these waves change according to the situation, being Ischemic or Hemorrhagic. Through the changing in waves and depending on the changing of magnetic flux density in the vessel design [14-17]. This treatment is highly dependent on time and cost from symptom onset to administration.

This paper primarily aims to provide a novel technique for early stroke detection, which reduces the risk of death or permanent disability. The mechanism of the technique is non-invasive by matching the radiation waves of healthy and infected as well. By finding a relationship between frequency, electric current, the nature of the coil and the number of its coils, where the experiment was carried out on the model that was designed according to several criteria, The study concluded with precise results and easy to differentiate between the different types of stroke, and on the other hand, the normal state through the resulting change in three scenarios (Normal, Ischemic and Hemorrhagic) Stroke. In this way, which can be developed later to be a device that can contribute to the early detection of stroke, we have begun to move towards a new method that may significantly reduce the risk of stroke as much as possible.

\section{Model Construction}

Based on the shortcomings in the current methods of stroke detection and identification, the use of a scenario in a non-intrusive manner was addressed by designing our simulation model, then, applying electromagnetic waves $[18,19]$, and measuring the change in results according to the three scenarios.
The model was designed- figure 1, using laminar flow [20-23] to represent the blood flow in venous, in normal Scenario, blood clotting in ischemic Scenario 2 through 3 positions, and vessel cut in hemorrhagic Scenario 3 through 9 positions. With a total of 13 models to represent all Scenarios with it is positions. The laminar flow in our designed model has defined the Inlet boundary condition as velocity (u), and the outlet boundary condition as pressure (p).

In addition, we surrounded this laminar flow by Homogenized multi-turn Coil as a conductor model that represent electromagnetic field [24-27]. The coil is Numeric, and coil magnetic vector potential is Quadratic, with current (A) to coil excitation as we need to see the Magnetic Flux Density MFD [28-32]. Our model is a Cartesian geometry $\{\mathrm{x}, \mathrm{y}, \mathrm{z}\}$ with a main parameter listed in table 1.

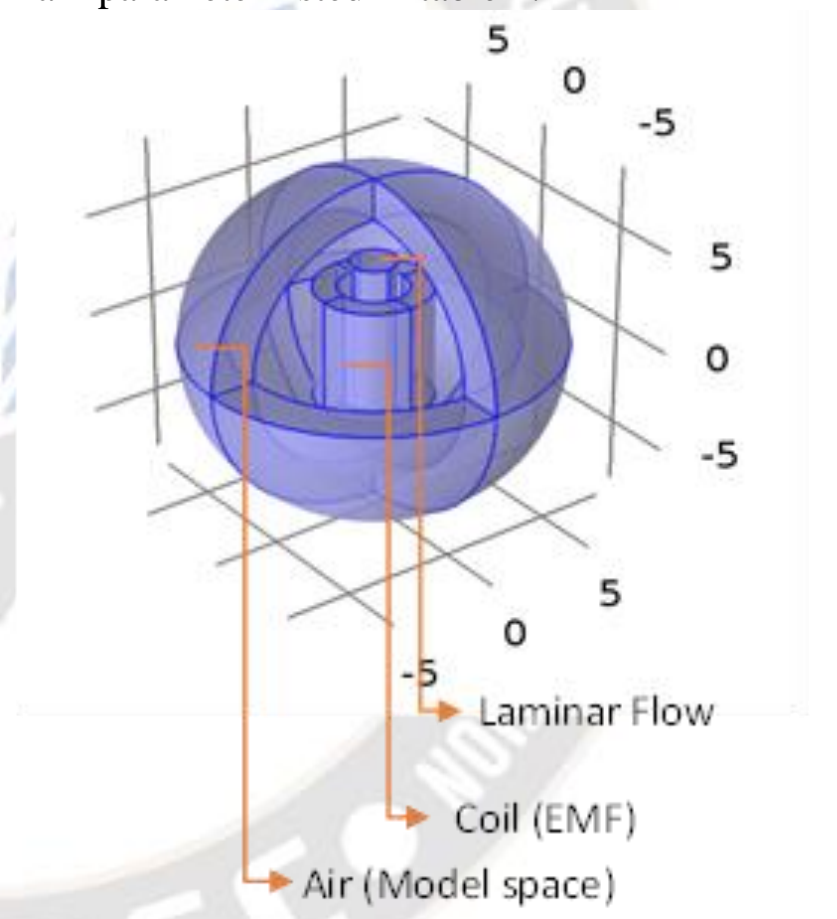

Fig 1: Model designed, Laminar flow surrounding by magnetic field 
Table 1: Model Basic parameters

\begin{tabular}{|c|c|c|c|}
\hline Name & Value & Description & Unit \\
\hline $\begin{array}{l}\text { Frequency - } \\
\text { F }\end{array}$ & $(10,15,20)$ & All & $\mathrm{Hz}$ \\
\hline $\begin{array}{c}\text { Relative } \\
\text { permeability }\end{array}$ & 1 & $\begin{array}{c}\text { Air } \\
\text { Material } \\
\text { parameter }\end{array}$ & $\mu \mathrm{r}$ \\
\hline $\begin{array}{c}\text { Relative } \\
\text { permittivity }\end{array}$ & 1 & $\begin{array}{c}\text { Air } \\
\text { Material } \\
\text { parameter }\end{array}$ & $E \mathrm{r}$ \\
\hline Coil current & $(0.5,1,1.5)$ & Coil-MF & A \\
\hline $\begin{array}{l}\text { Dynamic } \\
\text { viscosity }\end{array}$ & $1 \mathrm{~Pa} \cdot \mathrm{s}$ & Core & $\mu / \mathrm{mu}$ \\
\hline $\begin{array}{l}\text { Reference } \\
\text { temperature }\end{array}$ & $\begin{array}{l}293.15[\mathrm{~K}] \\
20[\mathrm{C}]\end{array}$ & $\begin{array}{l}\text { Laminar } \\
\text { Flow }\end{array}$ & $\mathrm{T}$ \\
\hline $\begin{array}{c}\text { Reference } \\
\text { pressure level }\end{array}$ & $1[\mathrm{~atm}]$ & $\begin{array}{l}\text { Laminar } \\
\text { Flow }\end{array}$ & \\
\hline $\begin{array}{c}\text { Blood } \\
\text { Density- rho }\end{array}$ & $1060 \mathrm{~kg} / \mathrm{m}^{3}$ & $\begin{array}{l}\text { Laminar } \\
\text { Flow }\end{array}$ & $\rho$ \\
\hline $\begin{array}{r}\text { Electrical } \\
\text { conductivity }\end{array}$ & 0 & $\begin{array}{c}\text { Air } \\
\text { Material } \\
\text { parameter }\end{array}$ & \\
\hline $\begin{array}{l}\text { Number of } \\
\text { turns }\end{array}$ & $(20,25)$ & Coil-MF & $\mathrm{n}$ \\
\hline $\begin{array}{c}\text { Coil } \\
\text { conductivity }\end{array}$ & $6 \mathrm{e} 7[\mathrm{~S} / \mathrm{m}]$ & Coil-MF & $\sigma(\mathrm{s} / \mathrm{m})$ \\
\hline Stabilization & Automatic & Coil-MF & - \\
\hline $\begin{array}{l}\text { Relative } \\
\text { permeability }\end{array}$ & $1 \mathrm{e} 3$ & Core & \\
\hline $\begin{array}{r}\text { Electrical } \\
\text { conductivity }\end{array}$ & 0 & Core & \\
\hline $\begin{array}{l}\text { Relative } \\
\text { permittivity }\end{array}$ & 1 & Core & \\
\hline Velocity & $\mathrm{u}$ & & $(\mathrm{m} / \mathrm{s})$ \\
\hline $\begin{array}{l}\text { Pressure/ } \\
\text { Absolute } \\
\text { pressure }\end{array}$ & $\mathrm{p}$ & & (pa) \\
\hline $\begin{array}{l}\text { Electric } \\
\text { Field- D }\end{array}$ & $\begin{array}{c}D=\in \\
0 \in \mathrm{rE}\end{array}$ & & \\
\hline $\begin{array}{l}\text { Magnetic } \\
\text { Vector } \\
\text { Potential } \\
\end{array}$ & A & & $\mathrm{Wb} / \mathrm{m}$ \\
\hline $\begin{array}{l}\text { Magnetic } \\
\text { Insulation }\end{array}$ & $=\mathrm{n} * \mathrm{~A}=0$ & & \\
\hline $\begin{array}{l}\text { Coil Length } \\
\text { Multiplication } \\
\text { factor }\end{array}$ & 1 & & $\mathrm{~F}_{\mathrm{L}}$ \\
\hline $\begin{array}{c}\text { Coil Area } \\
\text { Multiplication } \\
\text { factor }\end{array}$ & 1 & & $\mathrm{~F}_{\mathrm{A}}$ \\
\hline $\begin{array}{l}\text { Coil cross- } \\
\text { section area }\end{array}$ & $\begin{array}{c}= \\
\text { vire_rad^2} 2 * \text { pi }\end{array}$ & & $m 2$ \\
\hline $\begin{array}{l}\text { Ratio of } \\
\text { specific } \\
\text { heats }\end{array}$ & Gamma 1.4 & & 1 \\
\hline
\end{tabular}

Matrix of our models designed as shown in the three scenarios is shown in figure 2 to show graphical vessel- Normal, clotting, and cut positions

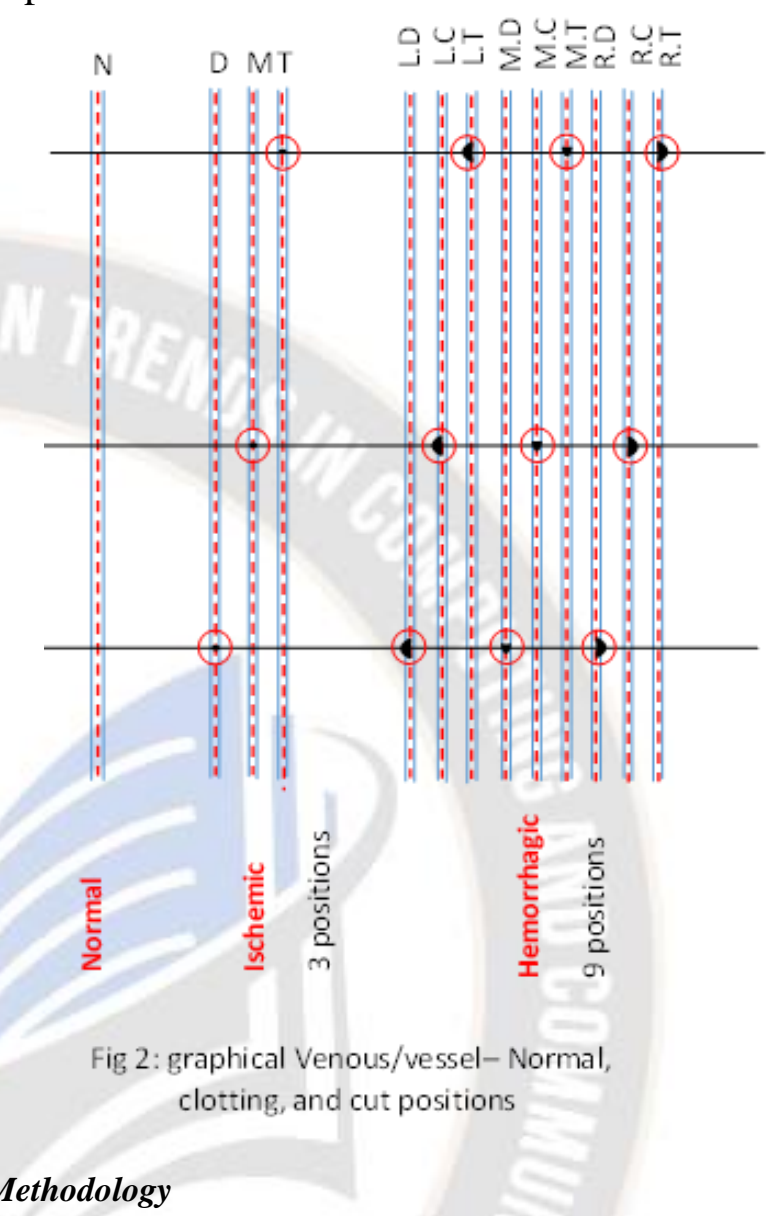

The researchers studied the multi-physics, which are (Magnetic fields and Laminar Flow) in the three areas: First: coil geometry analysis [33,34], Second: stationery [35-38], and Third: frequency domain [39-42].

In detailing the study there were many steps we will mention some of them. We started the study by compiling equations coil geometry analysis through magnetic vector potential and using a Linear solver with direct value in stationary solver1. Then we compile equation stationary 2 for magnetic vector potential with other dependent variables using Linear solver with Iterative value and Iterative solver value is FGMRS (flexible generalized minimum residual). The next step is to study stationary solver 3 for frequency domain using linear solver with iterative value, and iterative solver value is BicGStab (biconjugate gradient stabilized iterative method) 
Table 2: MFD norm for three scenarios in all positions designed in our models

\begin{tabular}{|c|c|c|}
\hline $\begin{array}{l}\text { Scenario } \\
\text { id }\end{array}$ & Name & $\begin{array}{l}\text { MFD- Magnetic } \\
\text { Flux Density }\end{array}$ \\
\hline $\begin{array}{c}\text { Scenario } \\
1\end{array}$ & $\begin{array}{l}\text { Normal blood } \\
\text { flow }\end{array}$ & $\begin{array}{l}\text { MFD }=0.09 \text { to } \\
3.3^{*} 10^{\wedge}-3\end{array}$ \\
\hline $\begin{array}{l}\text { Scenario } \\
\quad 2\end{array}$ & $\begin{array}{c}\text { Clotting: [3 } \\
\text { positions - Position } \\
\text { 1] Middle }\end{array}$ & $\begin{array}{l}\mathrm{MFD}=0.08 \text { to } \\
3.15^{*} 10^{\wedge}-4\end{array}$ \\
\hline $\begin{array}{l}\text { Scenario } \\
\quad 2\end{array}$ & $\begin{array}{l}\text { Clotting: [3 } \\
\text { positions - Position } \\
\text { 2] Above }\end{array}$ & $\begin{array}{l}\mathrm{MFD}=0.08 \text { to } \\
2.99 * 10^{\wedge}-4\end{array}$ \\
\hline $\begin{array}{l}\text { Scenario } \\
\quad 2\end{array}$ & $\begin{array}{c}\text { Clotting: [3 } \\
\text { positions - Position } \\
\text { 3] Down }\end{array}$ & $\begin{array}{l}\mathrm{MFD}=0.08 \text { to } \\
2.99 * 10^{\wedge}-4\end{array}$ \\
\hline $\begin{array}{l}\text { Scenario } \\
\quad 3\end{array}$ & $\begin{array}{l}\text { Cut: [9 positions } \\
\text { - Position 1] } \\
\text { Middle-Right }\end{array}$ & $\begin{array}{l}\mathrm{MFD}=0.18 \text { to } \\
6.91 * 10^{\wedge}-3\end{array}$ \\
\hline $\begin{array}{l}\text { Scenario } \\
\quad 3\end{array}$ & $\begin{array}{c}\text { Cut: [9 positions } \\
\text { - Position 2] Top- } \\
\text { Right }\end{array}$ & $\begin{array}{l}\mathrm{MFD}=0.15 \text { to } \\
5.96^{*} 10^{\wedge}-3\end{array}$ \\
\hline $\begin{array}{l}\text { Scenario } \\
\quad 3\end{array}$ & $\begin{array}{c}\text { Cut: [9 positions } \\
\text { - Position 3] Down- } \\
\text { Right }\end{array}$ & $\begin{array}{l}\mathrm{MFD}=0.17 \text { to } \\
6.69 * 10^{\wedge}-3\end{array}$ \\
\hline $\begin{array}{l}\text { Scenario } \\
\quad 3\end{array}$ & $\begin{array}{c}\text { Cut: [9 positions } \\
\text { - Position 4] Top- } \\
\text { Left }\end{array}$ & $\begin{array}{l}\mathrm{MFD}=0.59 \text { to } \\
6.89 * 10^{\wedge}-3\end{array}$ \\
\hline $\begin{array}{l}\text { Scenario } \\
\quad 3\end{array}$ & $\begin{array}{l}\text { Cut: [9 positions } \\
\text { - Position 5] } \\
\text { Middle-Left }\end{array}$ & $\begin{array}{l}\mathrm{MFD}=0.16 \text { to } \\
5.82 * 10^{\wedge}-3\end{array}$ \\
\hline $\begin{array}{l}\text { Scenario } \\
\quad 3\end{array}$ & $\begin{array}{l}\text { Cut: [9 positions } \\
\text { - Position 6] Down- } \\
\text { Left }\end{array}$ & $\begin{array}{l}\mathrm{MFD}=0.15 \text { to } \\
5.56^{*} 10^{\wedge}-3\end{array}$ \\
\hline $\begin{array}{l}\text { Scenario } \\
\quad 3\end{array}$ & $\begin{array}{l}\text { Cut: [9 positions } \\
\text { - Position 7] Top- } \\
\text { Middle }\end{array}$ & $\begin{array}{l}\text { MFD }=0.1 \text { to } \\
4.06^{*} 10^{\wedge}-3\end{array}$ \\
\hline $\begin{array}{l}\text { Scenario } \\
\quad 3\end{array}$ & $\begin{array}{l}\text { Cut: [9 positions } \\
\text { - Position 8] Midle- } \\
\text { Midle }\end{array}$ & $\begin{array}{l}\mathrm{MFD}=0.16 \text { to } \\
6.37 * 10^{\wedge}-3\end{array}$ \\
\hline $\begin{array}{l}\text { Scenario } \\
\quad 3\end{array}$ & $\begin{array}{c}\text { Cut: [9 positions } \\
\text { - Position 9] Down- } \\
\text { Middle }\end{array}$ & $\begin{array}{l}\mathrm{MFD}=0.15 \text { to } \\
5.82 * 10^{\wedge}-3\end{array}$ \\
\hline
\end{tabular}

\section{Model Materials, Domains, and Boundaries}

Simulation notation of geometry (volume, surfaces, lines, and points) and processed "Entities" Domains, Boundaries, and if applicable edges and points. Common domain was used as mentioned bellow, with note some changes depending on the different Scenario and equations is applied in all scenarios Our designed geometries for three scenarios to represent 14 different positions to measure the changing in MFD - Magnetic Flux Density [9], as described below:

\section{Domains and Boundaries specifications}

Figure bellow describe the Magnetic Fields Domains (1-14)

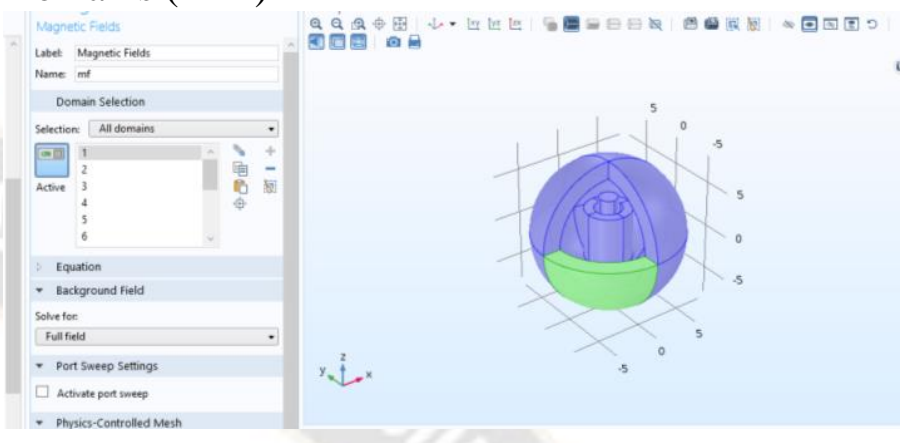

Figure bellow describe the Air Domains (1-7, 9-14)

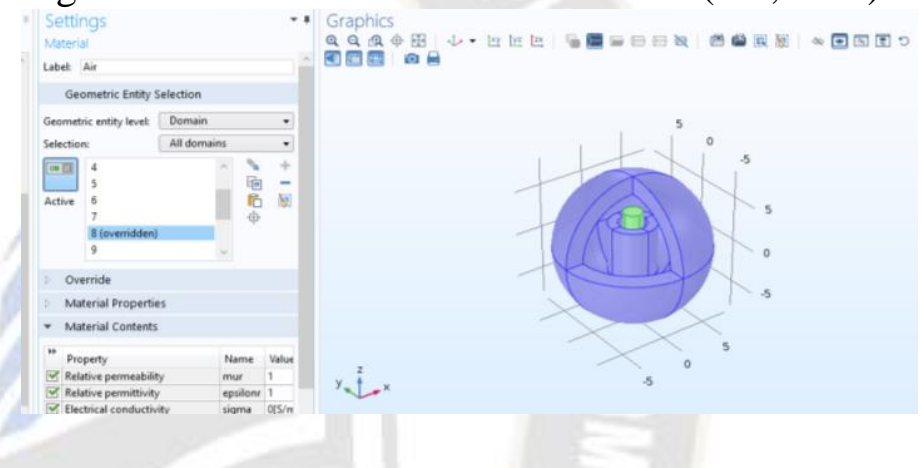

Figure bellow describe the Core Domain (8)

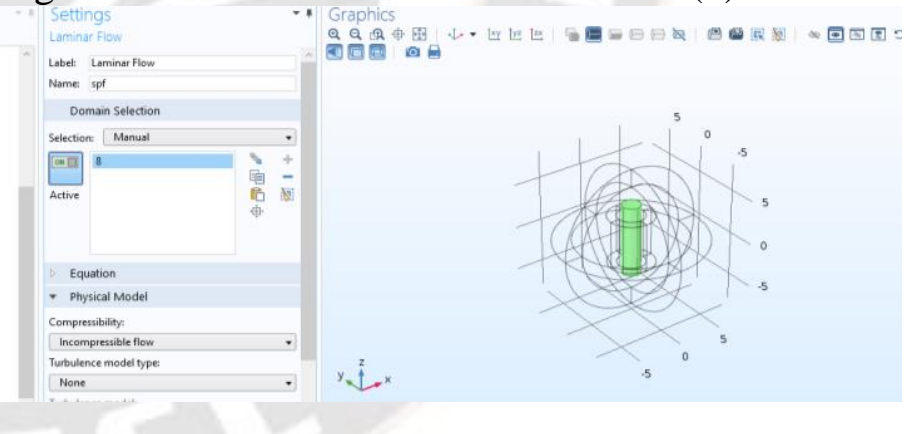

Figure bellow describe the Ampere Low (Domains 1$5,8-10,12-13)$

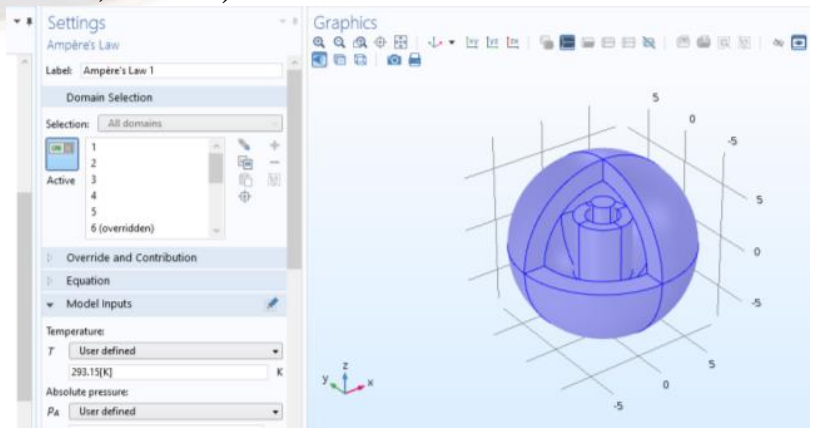


Figure bellow describe the Magnetic Insulation Boundaries $(5-8,29-30,41,46)$

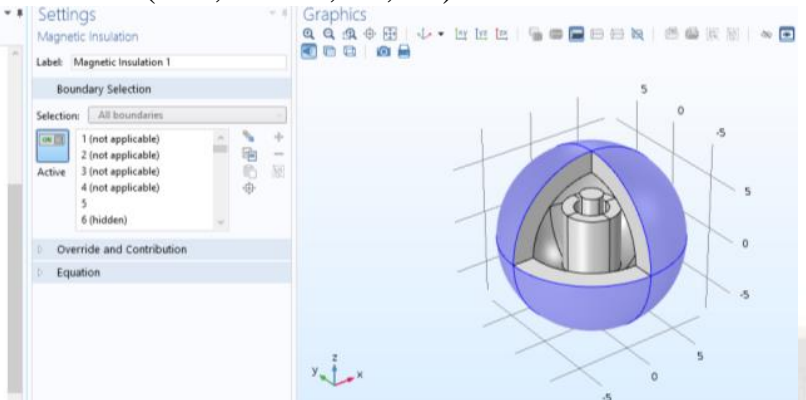

Figure bellow describe the Coil Domains $(6-7,11$, 14)

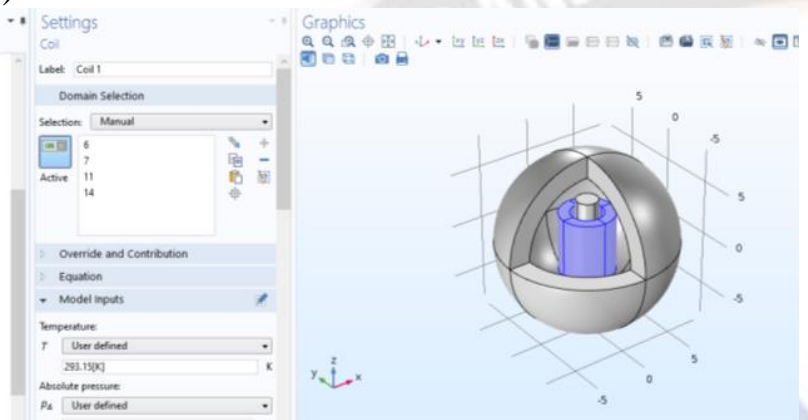

Figure bellow describe the Geometry Analytics Domains $(6-7,11,14)$
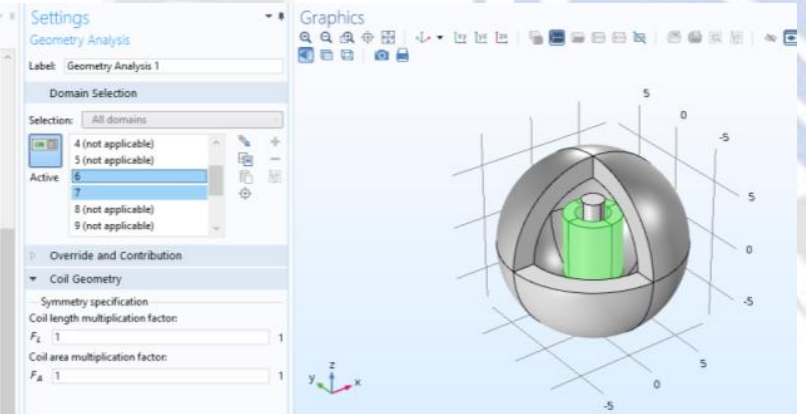

Figure bellow describe the Wall (Boundaries 22-23, $38,47)$

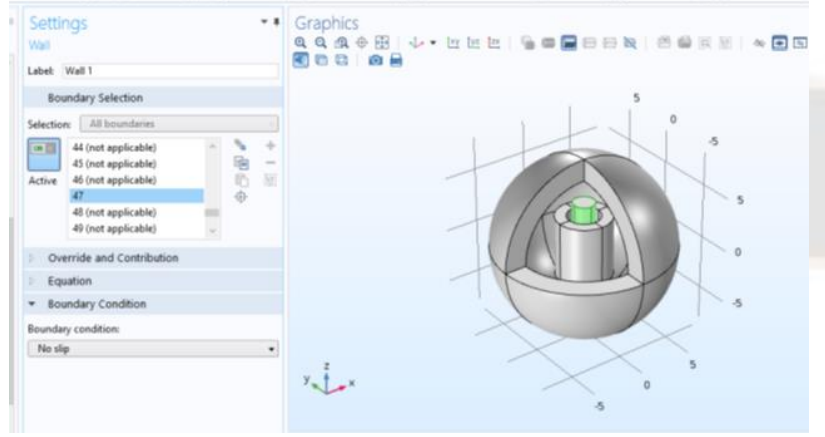

Scenario 1: For normal blood flow (N)

Magnetic fields (Domains 1-14), Air (Domains 17, 9-14), Core (Domain 8), Ampere Low (Domains $1-5,8-10,12-13)$ using the equation (1) $\nabla * H=J$, where $H$ is magnetic field, $J$ is current density. And equation (2) $\mathrm{B}=\nabla * A$, where $B$ isutive relation, $A$ is coil current, and equation (3) $\mathrm{J}=\sigma E$, where $\sigma$ is coil conductivity.

Magnetic Insulation (Boundaries 5-8, 29-30, 41, 46) with equation (4) $n * A=0$, Coil (Domains 6-7, $11,14)$ using equation (5) J_e $e=N I c o i l / A$ ecoil , Geometry Analytics (Domains 6-7, 11, 14), Input (Boundary 13) for magnetic field see the fig 3, Laminar Flow (Domain 8) see the figure 4 with equations (6) $\quad=\nabla \cdot\left[-\rho I+\mu\left(\nabla \mathrm{u}+(\nabla \mathrm{u})^{\wedge} \mathrm{T}\right)\right]+\mathrm{F}$, $\rho \nabla .(u)=0$, Wall (Boundaries 22-23, 38, 47) using equation $\mathrm{U}=0$, , Inlet (Boundary 24) see the figure 8 using equation $\mathrm{u}=-\mathrm{U} 0 \mathrm{n}$, Outlet (Boundary 25) see the figure 9 using equations (7) $\llbracket[-\rho \rrbracket$ $\left[I+\mu\left(\nabla \mathrm{u}+(\nabla \llbracket u) \rrbracket{ }^{\wedge} T\right)\right] \mathrm{n}=-\rho 0 \mathrm{n}, \rho_{-}^{\wedge} 0 \leq \rho \_0$. With fluid properties equations $(\mathbf{8})=\nabla[-\rho I+\mu(\nabla \mathrm{u}+(\nabla \mathrm{u})$ $\left.\left.{ }^{\wedge} \mathrm{T}\right)\right]+\mathrm{F}, \rho \nabla(u)=0$
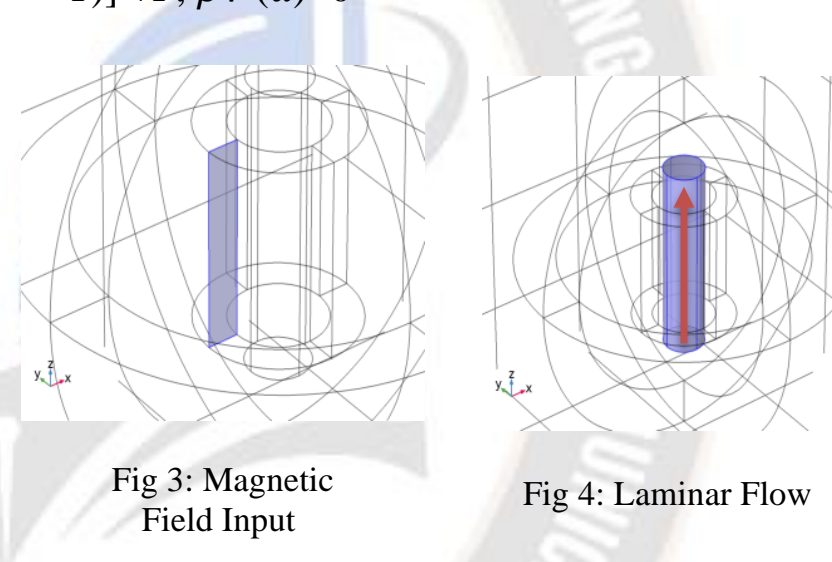

Fig 4: Laminar Flow

Scenario 2: For clotting/Ischemic stroke which have three positions, Top (T), middle (M) and down (D) of vessel designed.

Magnetic fields (Domains 1-75), Air (Domain 1-6, 10-42, 44-73, 75), Core (Domains 7-9, 43, 74), Ampere Low (Domains 1-4, 7-41, 43-74) using equations (1) (2), (3), Magnetic Insulation (Boundaries 5-12, 14-25, 107-110, 112-116, 164$165,168-169,215,217-220)$ using equation (4), Coil (Domains 5-6, 42, 75) using equation (5), Geometry Analytics (Domains 5-6, 42, 75), Input (Boundary 13), Laminar Flow (Domains 7-9, 43, 74) using equation (6), Wall (Boundaries 22-23, 32-33, 35-36, 41, 51-52, 83-84, 93, 99-103, 116, 121, 123, 132, $151,160-161,171,174,181,191,210,212,215)$, Inlet (Boundary 24), Outlet (Boundary 25) using equation (7). 
Scenario 3: For cutting/ Hemorrhagic stroke which have nine positions, 3 Right (Top, middle and down), 3 Center (Top, middle and down), 3 Left (Top, middle and down). See the figures Figure 5, Figure 6, and Figure 7, respectively.

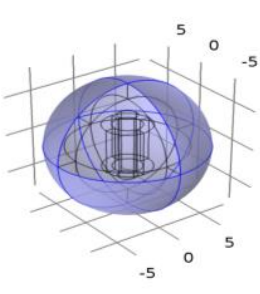

Fig 5: Model in Normal Scenario

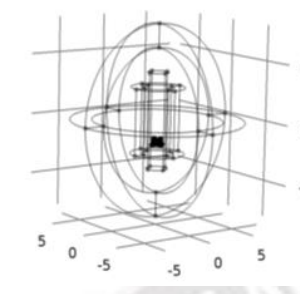

Fig 6: Model in
Clotting scenario
Ischemic) position 3 down

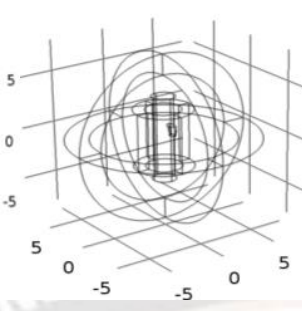

Fig 7: Model in cut scenario (Ischemic) position 1- TopRight TR)
Magnetic fields (Domains 1-14), Air (Domains 1-7, 9-14), Core (Domain 8), Ampere Low (Domains 15, 8-10, 12-13) using equations (1) (2), (3), Magnetic Insulation (Boundaries 5-8, 29-30, 41, 46) using equation (4), Coil (Domains 6-7, 11, 14) using equation (5),

Geometry Analytics (Domains 6-7, 11, 14), Input (Boundary 13), Laminar Flow (Domain 8) using equation (6), Wall (Boundaries 22-23, 38, 47, 5459), Inlet (Boundary 24), Outlet (Boundary 25) using equation (7).

In All three scenarios the stationary solver 1 with segregated 1 using termination technique with value iterations or tolerance, with the number of iterations 6 , it had two segregated steps with linear solver with direct value.

The stationary 2 compiled the equations with dependent variables, with 150 as a maximum number of iterations and linear solver value is iterative, in addition, velocity $\mathrm{u}$, pressure $\rho$. also using direct linear solver with the number of iteration value 2 for auxiliary space Maxwell (AMS) and direct solver value is PARDISO (Parallel Direct Sparse Solver for Clusters).

The stationary solver 3 is defined by the study step for frequency domain set at $15 \mathrm{HZ}$, and fully coupled linear solver with iterative value. In addition, iterative solver value is BicGStab (biconjugate gradient stabilized iterative method). in this section we have table 2 bellow that describing the results for all scenarios with it is all positions To ensure that our main parameters which are frequency $\mathrm{F}$, Current $\mathrm{A}$ and Coil number of turns $\mathrm{N}$, we tried to fix the current, and changing the values for coil turns and frequency, then fixing the frequency and change the current and coil current, and finally we fixed the coil turns and change the current and the frequency. And this is happened in many scenarios, we found that no change in MFD - Magnetic flux density norm results when we change the frequency. at the same time A and $\mathrm{N}$ fixed, table 3 show some results for normal Scenario, as the Magnetic flux density norm depend on / affected by the A and $\mathrm{N}$ only:

Table 3: Results for MFD, $\mathrm{F}$ is changing, $\mathrm{A}$ and $\mathrm{N}$ are fixed $0.5 \mathrm{~A}, 20$ Turns

\begin{tabular}{ccccc}
\hline$\#$ & $\begin{array}{c}\text { Frequency } \\
(\mathbf{F})\end{array}$ & $\begin{array}{c}\text { Current } \\
(\mathbf{A})\end{array}$ & $\begin{array}{c}\text { Coil } \\
(\mathbf{N})\end{array}$ & $\begin{array}{c}\text { MFD } \\
\text { norm }\end{array}$ \\
\hline 1 & $10 \mathrm{~Hz}$ & $0.5 \mathrm{~A}$ & 20 & $\begin{array}{c}0.03 \text { to } \\
1.32 * 10^{\wedge-3}\end{array}$ \\
& & & & 0.03 to \\
2 & $15 \mathrm{~Hz}$ & $0.5 \mathrm{~A}$ & 20 & $1.32^{*} 10^{\wedge-3}$ \\
\hline 3 & $20 \mathrm{~Hz}$ & $0.5 \mathrm{~A}$ & 20 & $\begin{array}{c}0.03 \text { to } \\
1.32^{*} 10^{\wedge-3}\end{array}$ \\
\hline
\end{tabular}

While fixing the Current $\mathrm{A}$, and increasing the coil turns $\mathrm{N}$, in same Scenario and frequency is changes, the increase in coil $\mathrm{N}$ in effected by 0.3 in MFD norm, table 4 is showing some results:

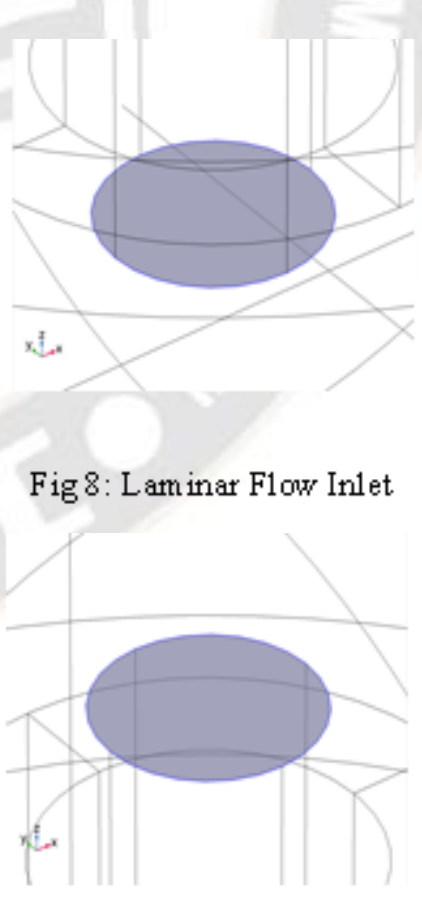

Fig 9: Laminar Flow Outlet

Table 4: Results for MFD, $\mathrm{F}$ is changing, $\mathrm{A}$ and $\mathrm{N}$ are fixed $0.5 \mathrm{~A}, 25$ Turns 


\begin{tabular}{ccccc}
\hline \hline$\#$ & $\begin{array}{c}\text { Frequency } \\
(\mathbf{F})\end{array}$ & $\begin{array}{c}\text { Current } \\
(\mathbf{A})\end{array}$ & $\begin{array}{c}\text { Coil } \\
(\mathbf{N})\end{array}$ & MFD norm \\
\hline 4 & $10 \mathrm{~Hz}$ & $0.5 \mathrm{~A}$ & 25 & $\begin{array}{c}0.04 \text { to } \\
1.65 * 10^{\wedge^{-3}}\end{array}$ \\
\hline 5 & $15 \mathrm{~Hz}$ & $0.5 \mathrm{~A}$ & 25 & $\begin{array}{c}0.04 \text { to } \\
1.65 * 10^{\wedge^{-3}}\end{array}$ \\
\hline 6 & $20 \mathrm{~Hz}$ & $0.5 \mathrm{~A}$ & 25 & 0.04 to \\
& & & & $1.65^{*} 10^{\wedge^{-3}}$ \\
\hline
\end{tabular}

In addition, the increasing of current (double $1 \mathrm{~A}$ ) while frequency is changing and the coil $\mathrm{N}$ is fixed as shown in table 5, the MFD norm results became two times (double), and the results show that in $0.5 \mathrm{~A}$ the MFD value was 0.03 to $1.32 * 10^{\wedge}-3$ and in $1 \mathrm{~A}$ the MFD value was 0.07 to $2.46^{*} 10^{\wedge}-3$

Table 5: Results for MFD, $\mathrm{F}$ is changing, $\mathrm{A}$ and $\mathrm{N}$ are fixed $1 \mathrm{~A}, 20$ Turns

\begin{tabular}{ccccr}
\hline$\#$ & $\begin{array}{c}\text { Frequency } \\
(\mathbf{F})\end{array}$ & $\begin{array}{c}\text { Current } \\
(\mathbf{A})\end{array}$ & $\begin{array}{c}\text { Coil } \\
(\mathbf{N})\end{array}$ & \multicolumn{1}{c}{$\begin{array}{c}\text { MFD } \\
\text { norm }\end{array}$} \\
\hline 7 & $10 \mathrm{~Hz}$ & $1 \mathrm{~A}$ & 20 & $\begin{array}{r}0.07 \text { to } \\
2.46 * 10^{\wedge^{-3}}\end{array}$ \\
\hline 8 & $15 \mathrm{~Hz}$ & $1 \mathrm{~A}$ & 20 & $\begin{array}{r}0.07 \text { to } \\
2.46 * 10^{-3}\end{array}$ \\
\hline 9 & $20 \mathrm{~Hz}$ & $1 \mathrm{~A}$ & 20 & $\begin{array}{r}0.07 \text { to } \\
\end{array}$ \\
& & & & $2.46 * 10^{\wedge^{-3}}$ \\
\hline
\end{tabular}

By implementing $1.5 \mathrm{~A}$, as shown in Table 6 , the MFD norm results became three times when we used $0.5 \mathrm{~A}$ and this is mean that, the changing in frequency did not make any difference, while the increase in coil turns $\mathrm{N}$ is affecting the MFD value, also increasing the current $A$ is very effective with $\mathrm{N}$ as they are the main effect of MFD norm value. The same tries were run on the other scenarios (clotting \& Hemorrhagic), and the analysis of the result is the same.

Table 6: Results for MFD, $\mathrm{F}$ is changing, $\mathrm{A}$ and $\mathrm{N}$ are fixed 1.5 A, 20

\begin{tabular}{ccccr}
\hline$\#$ & $\begin{array}{c}\text { Frequency } \\
(\mathbf{F})\end{array}$ & $\begin{array}{c}\text { \& } 25 \text { Turns } \\
\text { Current }\end{array}$ & $\begin{array}{c}\text { Coil } \\
(\mathbf{N})\end{array}$ & $\begin{array}{c}\text { MFD } \\
\text { norm }\end{array}$ \\
\hline \multirow{2}{*}{10} & $10 \mathrm{~Hz}$ & $1.5 \mathrm{~A}$ & 20 & $\begin{array}{c}0.1 \text { to } \\
3.96^{*} 10^{\wedge^{-3}}\end{array}$ \\
\hline \multirow{2}{*}{11} & $15 \mathrm{~Hz}$ & $1.5 \mathrm{~A}$ & 20 & $\begin{array}{r}0.07 \text { to } \\
2.46^{*} 10^{\wedge^{-3}}\end{array}$ \\
\hline \multirow{2}{*}{12} & $20 \mathrm{~Hz}$ & $1.5 \mathrm{~A}$ & 20 & $\begin{array}{r}0.07 \text { to } \\
2.46^{*} 10^{\wedge^{-3}}\end{array}$ \\
\hline \multirow{2}{*}{13} & $10 \mathrm{~Hz}$ & $1.5 \mathrm{~A}$ & 25 & $\begin{array}{r}0.13 \text { to } \\
4.95^{*} 10^{\wedge^{-3}}\end{array}$ \\
\hline \multirow{2}{*}{14} & $15 \mathrm{~Hz}$ & $1.5 \mathrm{~A}$ & 25 & $\begin{array}{r}0.13 \text { to } \\
4.95 * 10^{\wedge^{-3}}\end{array}$ \\
\hline
\end{tabular}

\section{Results}

According to the results obtained in all scenarios, we found a clear difference and change in the shape of Magnetic Flux Density norm, and it is value, as we find the best differentiation between all scenarios, and we choose to study our model at frequency $15 \mathrm{~Hz}$, current $1 \mathrm{~A}$, and coil number of turns 25. results in table 2, The main scenarios result show that there are different values of the waves that can help us predict the stroke type through normal, clotting/Ischemic, and cutting/Hemorrhagic scenarios. The results represented in the figures below from figure 10 22 represent all scenarios respectively:

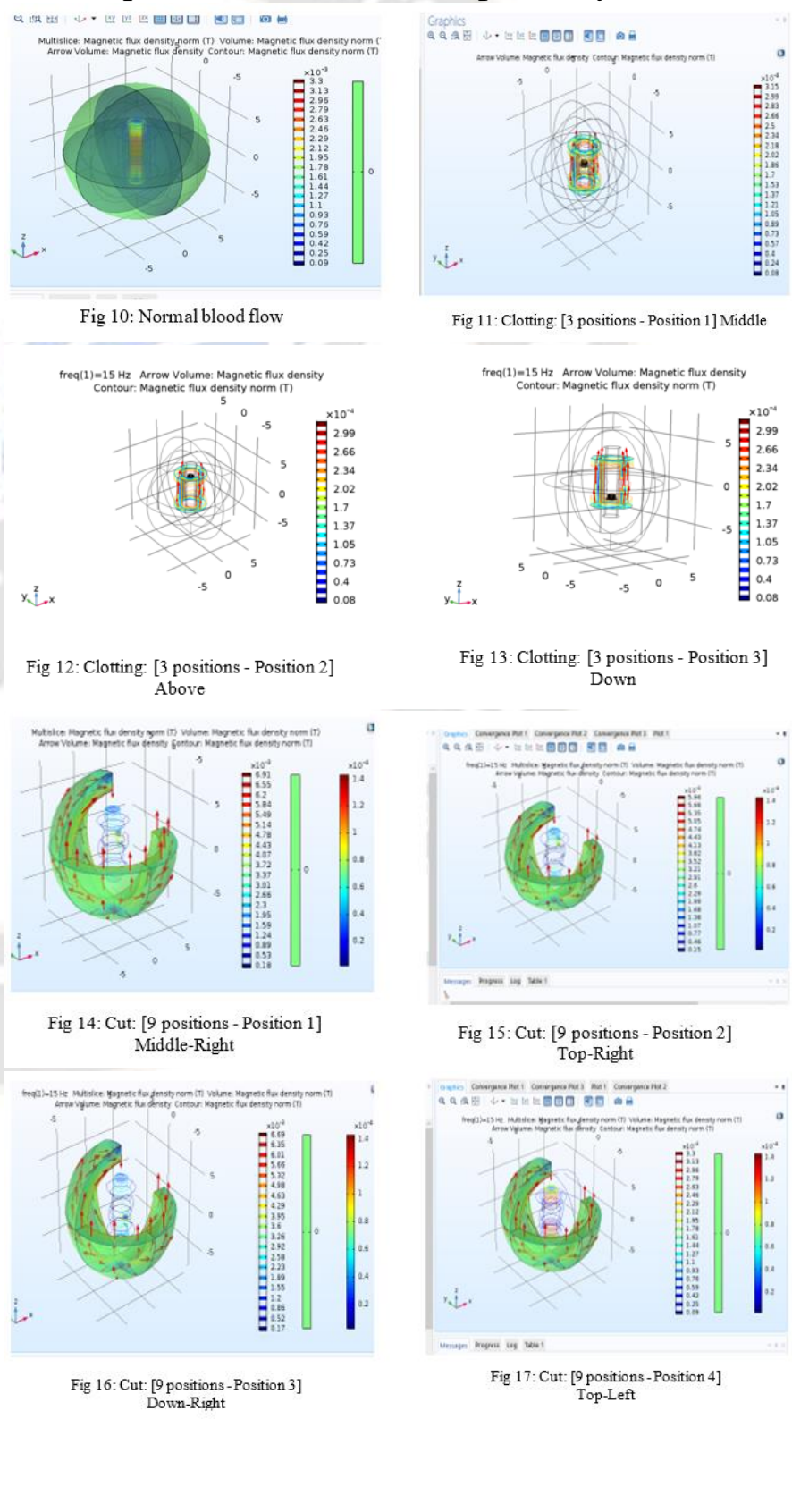




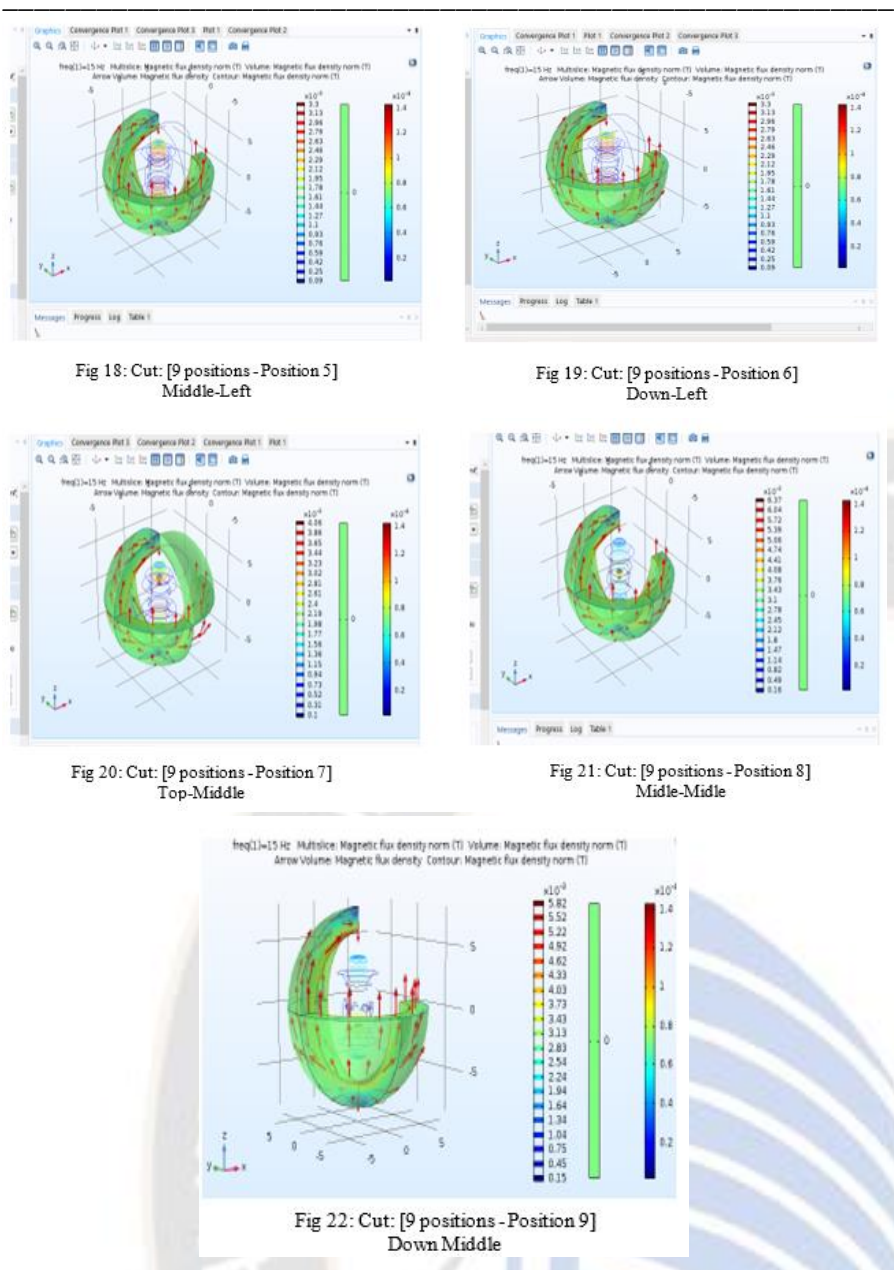

From the above-mentioned results, an average was extracted, where the scenario was $=0$, scenario $1=$ from 0.09 to 0.0033 , scenario $2=0.08$ to 0.000315 , and scenario $3=0.15$ to 0.0062 . the results are graphically represented in figure 23.

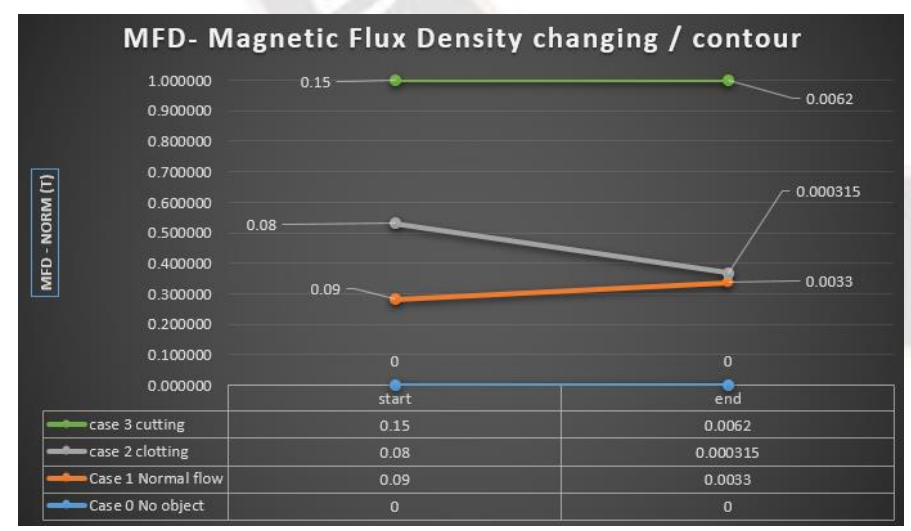

\section{Discussion}

Fig 23: Results representation

Through our approach to distinguishing stroke types in a non-invasive way, and according to the model that was designed which includes the base scenarios with a variety of positions, and by changing the basic values of the most influential parameters, the researchers found a solid indicator to approve that every Scenario has a different output in scenario exposure to radiation with low frequency. This help us to quickly define the stroke type and start the first step of medication that can help the patient because it is many times not appear as a result in MRI and we must wait for second scanning after 6 hours minimally, this may lead to a further deterioration of the condition and delay in its treatment, which causes common complications of the disease. Through this research, in the future we can design a hardware device using same software features we applied in this research to detect and measure magnetic field changes as a result of MFD and move this simulation work to be real to know the type and this is very cheap, fast, and safe in human real scenarios. And by calculating the average for every Scenario, we obtain a chart prove that we can determine and detect each stroke type and normal Scenario.

\section{Conclusion}

Considering the available medical devices that detect stroke, and according to what was mentioned in the delay of these devices in the early detection of stroke, and through the purpose of our research to present a new method that contributes to the early detection of stroke in a non-invasive way, where the results indicated a difference Significant change in electromagnetic waves in the first scenario, which is the normal state, the value of MFD was 0.09 to $3.3^{*} 10^{\wedge}-3$. The second scenario was ischemic at ( 3 positions) and the average of them for MFD equal to 0.08 to $3.15^{*} 10^{\wedge}-4$, And third scenario was haemorrhagic at (9 positions), and the average of them for MFD equal to 0.15 to $6.2 * 10^{\wedge}-3$.

This contribution provided by the research is a very important beginning for the development of the sector of available devices technologies to detect stroke in a simpler, faster and less expensive way, which may contribute to the development of these devices or their evolution towards a gradual adoption of the use of electromagnetic waves in the early detection or identification of stroke in 
order to be Determine the appropriate treatment faster or the emergence of alternative devices that contribute to this direction, which is what we hope for the future in our upcoming research.

\section{References}

[1] R, C. (2016, July 1). Cervical vesseldissection: Early recognition and stroke prevention. Retrieved July 02, 2020, from https://europepmc.org/article/med/27315017

[2] R. C. (2020, December 15). Blunt cerebrovascular injuries: Early recognition and stroke prevention in the emergency department. Retrieved March 17, 2021, from https://europepmc.org/article/MED/33320488

[3 Hankey, G., \& Blacker, D. (2015, January 15). Is it a stroke? Retrieved May/June 2018, from https://www.bmj.com/content/350/bmj.h56.full.

[4] Krishna, A., Srinivasa Rao, P., \& Basha, C. Z. (2020). Computerized classification of Ct Lung images using CNN WITH WATERSHED SEGMENTATION. 2020 Second International Conference on Inventive Research in Computing Applications (ICIRCA). doi:10.1109/icirca48905.2020.9183203

[5] Dudoignon, B., Tainturier, L., Dodet, P., Bera, G., Groos, E., Chaumereuil, C., . . Arnulf, I. (2021, June 17). Functional brain imaging Using 18F-FLUORODEOXYGLUCOSE positron EMISSION Tomography/computerized tomography in 138 patients WITH kleine-levin syndrome: An EARLY MARKER? Retrieved July 04, 2021, from https://academic.oup.com/braincomms/article/3/2/fcab130/6 302554? login=true

[6] Ramzan, F., Khan, M. U., Iqbal, S., Saba, T., \& Rehman, A. (2020). Volumetric segmentation of brain regions from MRI scans using 3D convolutional neural networks. IEEE Access, 8, 103697-103709. doi:10.1109/access.2020.2998901

[7] Rosenberg, M. D., \& Song, H. (2020). Predicting post-stroke aphasia from brain imaging. Nature Human Behaviour, 4(7), 675-676. doi:10.1038/s41562-020-0902-1

[8] Xue, Y., Farhat, F. G., Boukrina, O., Barrett, A., Binder, J. R., Roshan, U. W., \& Graves, W. W. (2020). A multi-path 2.5 DIMENSIONAL convolutional neural network system for Segmenting stroke lesions in brain MRI images. NeuroImage: $\quad$ Clinical, $25, \quad 102118$. doi:10.1016/j.nicl.2019.102118

[9] Laurijn R. Draaisma, Maximilian J. Wessel, Friedhelm C. Hummel, Non-invasive brain stimulation to enhance cognitive rehabilitation after stroke, Neuroscience Letters, Volume 719, 2020, 133678, ISSN 0304-3940, https://doi.org/10.1016/j.neulet.2018.06.047.

(https://www.sciencedirect.com/science/article/pii/S030439 4018304506)

[10] Elena Olgiati \& Paresh A. Malhotra (2020) Using noninvasive transcranial direct current stimulation for neglect and associated attentional deficits following stroke, Neuropsychological Rehabilitation, DOI: 10.1080/09602011.2020.1805335

[11] Manuela Pastore-Wapp, Thomas Nyffeler, Tobias Nef, Stephan Bohlhalter, Tim Vanbellingen, Non-invasive brain stimulation in limb praxis and apraxia: A scoping review in healthy subjects and patients with stroke, Cortex, Volume
138, 2021, Pages 152-164, ISSN 0010-9452, https://doi.org/10.1016/j.cortex.2021.02.006.

[12](https://www.sciencedirect.com/science/article/pii/S00109452 21000630)

[13] Chao Sun, Xuehuan Liu, Cuiping Bao, Feng Wei, Yi Gong, Yiming Li, Jun Liu, Advanced non-invasive MRI of neuroplasticity in ischemic stroke: Techniques and applications, Life Sciences, Volume 261, 2020, 118365 , ISSN 0024-3205, https://doi.org/10.1016/j.lfs.2020.118365. (https://www.sciencedirect.com/science/article/pii/S002432 0520311188)

[14] Wang, W., Yang, D., \& Lu, Y. (2020). Modeling and simulation of vesselocclusion for early detection of carotid atherosclerosis. 2020 Chinese Control and Decision Conference (CCDC). doi:10.1109/ccdc49329.2020.9164358

[15] Hägglund, J. (2021, April 29). Simulated cerebrospinal fluid motion due to pulsatile arterial flow: Master thesis project. Retrieved May 04, 2021, from https://www.divaportal.org/smash/record.jsf?pid=diva2\%3A1546957\&dswid $=5929$

[16] Liu, Y., Yang, D., Duo, Y., Liu, G., Wang, W., \& Xu, B. (2020, March 6). Numerical model and finite element simulation of arterial blood flow profile reconstruction in a uniform magnetic field. Retrieved July 04, 2021, from https://iopscience.iop.org/article/10.1088/13616463/ab7325/meta

[17] Y. Wang and W. -N. Lee, "Non-Invasive Estimation of Localized Dynamic Luminal Pressure Change by Ultrasound Elastography in Arteries with Normal and Abnormal Geometries," in IEEE Transactions on Biomedical Engineering, vol. 68, no. 5, pp. 1627-1637, May 2021, doi: 10.1109/TBME.2020.3028186.

[18] Zhang, J., Liu, Y., Li, X., Shi, L., Yang, M., \& Bai, B. (2019). 2D simulation of the electromagnetic wave across the nonuniform reentry plasma sheath with COMSOL. AIP Advances, 9(5). doi:10.1063/1.5085876

[19] Arvin Farid, Atena Najafi, Jim Browning, Elisa Barney Smith, Electromagnetic waves' effect on airflow during air sparging, Journal of Contaminant Hydrology, Volume 220, 2019, ISSN 0169-7722, https://doi.org/10.1016/j.jconhyd.2018.11.004. (https://www.sciencedirect.com/science/article/pii/S016977 2218300019)

[20] Han, Z., Chen, J., Zhang, K., Xu, Z., Zhu, Z., \& Song, W. (2018). Aerodynamic shape optimization of natural-laminarflow wing using surrogate-based approach. AIAA Journal, 56(7), 2579-2593. doi:10.2514/1.j056661

[21] Juhyuk Park, Young Seok Song, Laminar flow manipulators, Extreme Mechanics Letters, Volume 40, 2020, 100908, ISSN 2352-4316, https://doi.org/10.1016/j.eml.2020.100908. (https://www.sciencedirect.com/science/article/pii/S235243 1620301723)

[22] Muhsun, S. S., Al-Sharify, 3. T., \& Bahiya, H. M. (2020, June 6). Simulation of Two-Phase Flow Contaminates Transport in Pipe Flow under Transient Laminar Flow Condition. Retrieved October 20, 2020, from https://www.researchgate.net/profile/Sadiq M/publication/343681706_Simulation_of_Two Phase_Flow_Contaminates_Transport_in_Pipe_Flow_under Transient_Laminar_Flow_Condition/links/5f38840f299bf 13 04c8515b/Simulation-of-Two-Phase-Flow-Contaminates Transport-in-Pipe-Flow-under-Transient-Laminar-Flow Condition.pdf 
[23] Acharya, Saroj., Analysis and FEM Simulation of Flow of Fluids in Pipes: Fluid Flow COMSOL Analysis, (2016)

[24] Vahid Nabaei, Rona Chandrawati, Hadi Heidari, Magnetic biosensors: Modelling and simulation, Biosensors and Bioelectronics, Volume 103, 2018, Pages 69-86, ISSN 09565663, https://doi.org/10.1016/j.bios.2017.12.023. (https://www.sciencedirect.com/science/article/pii/S095656 6317308229)

[25] Mohsen Sheikholeslami, Houman B. Rokni, Simulation of nanofluid heat transfer in presence of magnetic field: A review, International Journal of Heat and Mass Transfer, Volume 115, Part B, 2017, Pages 1203 1233, ISSN 00179310 ,

https://doi.org/10.1016/j.jheatmasstransfer.2017.08.108 (https://www.sciencedirect.com/science/article/pii/S001793 1017330004)

[26] Aidaoui, L., Lasbet, Y. \& Selimefendigil, F. Effect of simultaneous application of chaotic laminar flow of nanofluid and non-uniform magnetic field on the entropy generation and energetic/exergetic efficiency. J Therm Anal Calorim (2021). https://doi.org/10.1007/s10973-021-109050

[27] Hariri, S., Mokhtari, M., Gerdroodbary, M.B. et al. Numerical investigation of the heat transfer of a ferrofluid inside a tube in the presence of a non-uniform magnetic field. Eur. Phys. J. Plus 132, 65 (2017). https://doi.org/10.1140/epjp/i2017-11324-1

[28] Zhongjie Li, Yong Liu, Peilun Yin, Yan Peng, Jun Luo, Shaorong Xie, Huayan $\mathrm{Pu}$, Constituting abrupt magnetic flux density change for power density improvement in electromagnetic energy harvesting, International Journal of Mechanical Sciences, Volume 198, 2021, 106363, ISSN 0020-7403, https://doi.org/10.1016/j.ijmecsci.2021.106363. (https://www.sciencedirect.com/science/article/pii/S002074 0321000989)

[29] Ning, G., Chen, W., Ling, Y., Su, M., \& Xu, G. (2020). Magnetic flux density analysis of series resonant converter operating in discontinuous conduction mode for high-voltage high-power applications. IET Power Electronics, 13(18), 4386-4394. doi:10.1049/iet-pel.2020.0086

[30] Roldán-Blay, \& Roldán-Porta. (2020). Quick calculation of magnetic flux density in electrical facilities. Applied Sciences, 10(3), 891. doi:10.3390/app10030891

[31] F. Chu, Y. Fu, Q. Wang, X. Wu, Z. Liu and X. Lei, "Analysis of Static Magnetic Flux Density and Electromagnetic Force Distribution of a Dry-type Air-core Reactor Under Different Operating Current," 2019 22nd International Conference on Electrical Machines and Systems (ICEMS), 2019, pp. 1-4, doi: 10.1109/ICEMS.2019.8921978.

[32] P. Baskaran, D. Pasadas, H. Ramos and A. Ribeiro, "A Boundary Element Model of Perturbed Magnetic Flux Density Component in Eddy Current NDT of Flaws," 2021 Telecoms Conference (ConfTELE),IEEE 2021, pp. 1-4, doi: 10.1109/ConfTELE50222.2021.9435508.

Ulvr, M. (2020, June 22). AC MAGNETIC FLUX DENSITY STANDARDS AND THEIR USE IN METROLOGY. Retrieved July 04, 2021, from https://www.researchgate.net/profile/Michal-

Ulvr/publication/345319602_AC_magnetic_flux_density_st andards_and_their_use_in_metrology/links/5fa3b876299bf 1 0f732512a7/AC-magnetic-flux-density-standards-and-theiruse-in-metrology.pdf
[33] Qiu, L., Deng, K., Li, Y., Tian, X., Xiong, Q., Chang, P., . . Huang, L. (2020). Analysis of coil temperature rise in electromagnetic forming with coupled cooling method. International Journal of Applied Electromagnetics and Mechanics, 63(1). doi:10.3233/jae-190062

[34] Flaieh, E., Dwech, A., \& Mosheer, M. (2021, February 01). Modal Analysis of Fixed - Free Beam Considering Different Geometric Parameters and Materials. Retrieved July 04, 2021, from https://iopscience.iop.org/article/10.1088/1757899X/1094/1/012118/meta

[35] S.E. Savotchenko, Stationary states near the interface with anharmonic properties between linear and nonlinear defocusing media, Solid State Communications, Volume 283, 2018, ISSN 0038-1098, https://doi.org/10.1016/j.ssc.2018.08.002.

(https://www.sciencedirect.com/science/article/pii/S003810 9818301455)

[36] STURMA, M., NAMY, P., BRUYERE, V., \& BARBET, B. (n.d.). Modeling of charged droplet dynamics in an Electric Field using COMSOL Multiphysics. Retrieved July 04, 2020, from https://www.comsol.nl/paper/download/855251/Sturma_Ch argedDroplet-PT_ConfCOMSOL_20.pdf

[37] BRUYERE, V., NAMY, P., CRASSOUS, I., ALEX, F., \& CAVELLIN, C. D. (n.d.). Modeling of the Magnetic Field in a Vacuum Arc Remelting furnace using the COMSOL Multiphysics. Retrieved from Comsol.

[38] Y. Wang, L. -M. He, Z. Li, W. Xu and J. Ren, "A computationally efficient nonlinear dynamic model for cMUT based on COMSOL and MATLAB/Simulink," 2020 IEEE 15th International Conference on Solid-State \& Integrated Circuit Technology (ICSICT), 2020, pp. 1-3, doi: 10.1109/ICSICT49897.2020.9278134.

[39] Bekemeyer, P., Liverpool, U., Thormann, R., Timme, S., Albano E. and Rodden W. P., L., R., . . Timme, R. (2017, May 30). Frequency-domain gust response simulation using computational fluid dynamics. Retrieved July 04, 2019, from https://arc.aiaa.org/doi/abs/10.2514/1.J055373

[40] Z. -X. Du, A. Li, X. Y. Zhang and D. F. Sievenpiper, "A Simulation Technique for Radiation Properties of TimeVarying Media Based on Frequency-Domain Solvers," in IEEE Access, vol. 7, pp. 112375-112383, 2019, doi: 10.1109/ACCESS.2019.2935099.

[41] K. Takahashi, T. Ibuchi and T. Funaki, "Frequency domain simulation of conducted EMI in power electronic converters considering internal near field couplings by FEM," 2017 International Symposium on Electromagnetic Compatibility EMC EUROPE, 2017,IEEE.org, pp. 1-6, doi: 10.1109/EMCEurope.2017.8094780.

[42] A. V. Syutkin, G. A. Evdokunin and I. V. Popov, "Methodology of Determining Frequency Response of Grounding Systems Using the COMSOL Multiphysics Software," 2021 IEEE Conference of Russian Young Researchers in Electrical and Electronic Engineering (ElConRus), 2021, pp. 1289-1292, doi: 10.1109/ElConRus51938.2021.9396194. 